\title{
CORRECTION
}

\section{Correction to: Novel quantitative and objective structured assessment of technical skill for slip knotting}

\author{
Shun Watanabe ${ }^{1} \cdot$ Tetsuya Kitagawa $^{1} \cdot$ Kazutoshi Tachibana $^{1} \cdot$ Hiroyuki Kurosawa ${ }^{1} \cdot$ Kiyoshi Chiba $^{1} \cdot$ Joji Ito $^{1}$. \\ Makoto Hibino $^{1} \cdot$ Masaki Taira $^{1} \cdot$ Takahiro Taguchi $^{1} \cdot$ Masanori Nishimura $^{1}$
}

Published online: 8 November 2019

(c) The Japanese Association for Thoracic Surgery 2019

\section{Correction to: General Thoracic and Cardiovascular Surgery https://doi.org/10.1007/s11748-019-01222-3}

The article "Novel quantitative and objective structured assessment of technical skill for slip knotting", written by Shun Watanabe, Tetsuya Kitagawa, Kazutoshi Tachibana, Hiroyuki Kurosawa, Kiyoshi Chiba, Joji Ito, Makoto Hibino, Masaki Taira, Takahiro Taguchi, Masanori Nishimura, was originally published electronically on the publisher's internet portal (currently SpringerLink) on 15 October 2019 with open access. With the author(s)' decision to step back from Open Choice, the copyright of the article changed on 8 November 2019 to $@$ The Japanese Association for Thoracic
Surgery 2019 and the article is forthwith distributed under the terms of copyright.

The original article has been corrected.

Publisher's Note Springer Nature remains neutral with regard to jurisdictional claims in published maps and institutional affiliations.
The original article can be found online at https://doi.org/10.1007/ s11748-019-01222-3.

Shun Watanabe

shunchan828@me.com

1 The committee of The Japanese Society for Cardiovascular Surgery Under-Forty, 2-26-9, Hongou, Bunkyo-ku,

Tokyo 113-0033, Japan 